\title{
A DNA betasatellite - begomovirus complex associated with leaf curl disease of Cardiospermum microcarpum (Kunth)
}

\author{
N. Salim ${ }^{1 *} \&$ A.N.W.S. Thushari ${ }^{2}$ \\ ${ }^{1}$ Department of Botany, Faculty of Applied Sciences, University of Sri Jayewardenepura, Gangodawila, Nugegoda. \\ 2 Microbiology Division, Sugarcane Research Institute, Uda Walawe.
}

Revised: 11 November 2009; Accepted: 19 February 2010

Keywords: Begomovirus, Cardiospermum microcarpum (Kunth), Cotton leaf curl Multan betasatellite, DNA betasatellite.

Cardiospermum halicacabum L. var. microcarpum Kunth (Balloon wine, Sinhala vernacular name-penela val) is a weed grown in Asia, Africa, Australia and America. It has a high medicinal value and the whole plant is used both externally and internally in snakebites, to cure rheumatism and nervous diseases, dropsy and orchitis ${ }^{1}$. The herb is also a nutritious leafy vegetable and therefore, grown in home gardens as it provides a supplementary income to families with low income.

Leaf curl or yellow leaf curl symptoms, which are characteristic of begomovirus infection, was noticed in this herb growing in the Colombo region, in 2004. The disease was later found to occur in several other places such as Kandy, Gampola, Ratnapura, Horana and Embilipitya. Begomoviruses have either monopartite or bipartite genomes. A considerable number of monopartite begomoviruses are associated with an additional DNA molecule known as DNA betasatellite which is approximately $1.4 \mathrm{~kb}$ in size ${ }^{2}$. The DNA betasatellites depend on their helper begomoviruses for replication, movement within plants and to be insect transmitted while modulating the symptoms caused by the helper begomovirus. These DNA betasatellite-begomovirus complexes are reported to be associated with a number of economically important diseases in Africa and Asia, causing yield losses estimated as millions of US dollars. Although more than 100 distinct begomoviruses have been characterized to date, only a very few published information is available on begomovirus species and their hosts in Sri Lanka ${ }^{3,4}$. Herein we report the occurrence of a DNA betasatellite-begomovirus complex in C. microcarpum (Kunth) with leaf curl disease, prevalent in the Colombo region.

Samples of leaves of C. microcarpum (Kunth) plants, showing leaf curl symptoms were collected from five individual plants growing in different locations, namely, Nugegoda (C0-1), three sites at Maharagama (C0-2, $\mathrm{C} 0-3$ and $\mathrm{C} 0-4)$ and Wijerama ( $\mathrm{C} 0-5)$. The Maharagama isolate $\mathrm{C} 0-2$ showed yellowing in addition to upward leaf rolling while all other samples showed only leaf rolling symptoms (Figure 1).

Two serological tests were used to identify the presence of begomoviruses in these samples. For chloroplast agglutination test ${ }^{5}$, the leaf extract was prepared from symptomatic and asymptomatic plants separately by grinding $1 \mathrm{~g}$ of infected leaf sample in $1 \mathrm{~mL}$ of distilled water. Aliquots of $10 \mu \mathrm{L}$ of crude extracts were separately placed on a clean glass microscopic slide. Same volume of a monoclonal antibody, SCR 60, produced against a begomovirus, namely, Indian cassava mosaic virus (ICMV) isolate was added on to each sample of crude extract and examined for agglutination. Further confirmation of the presence of a begomovirus was achieved by indirect triple antibody sandwich enzyme linked immunosorbent assay (TAS ELISA) using a well-established protocol ${ }^{6}$. The SCR 60 and Immunoglobulin $\mathrm{G}(\mathrm{IgG})$ of African cassava mosaic virus (ACMV) antiserum were used in the ELISA test.

To ascertain whether a DNA betasatellite molecule is associated with the begomovirus in these samples, the DNA was extracted from $0.1 \mathrm{~g}$ of leaf tissues infected with C. microcarpum (Kunth) using Nucleon Plant DNA 


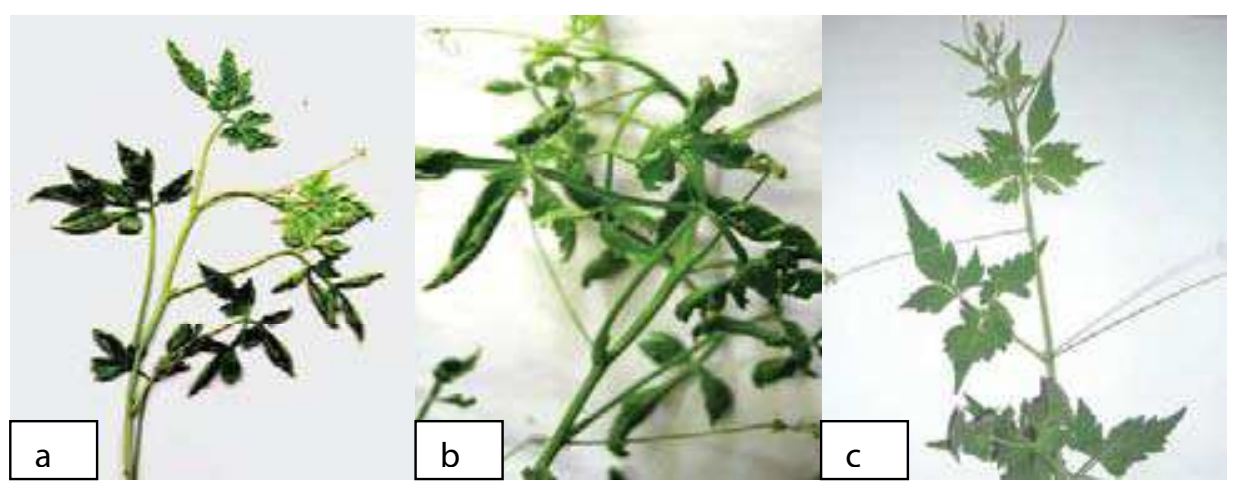

Figure 1: C. microcarpum showing a) Yellow leaf curl symptom of isolate C0-2; (b) Leaf curl symptom of isolate $\mathrm{C} 0-4$; c) Asymptomatic plant

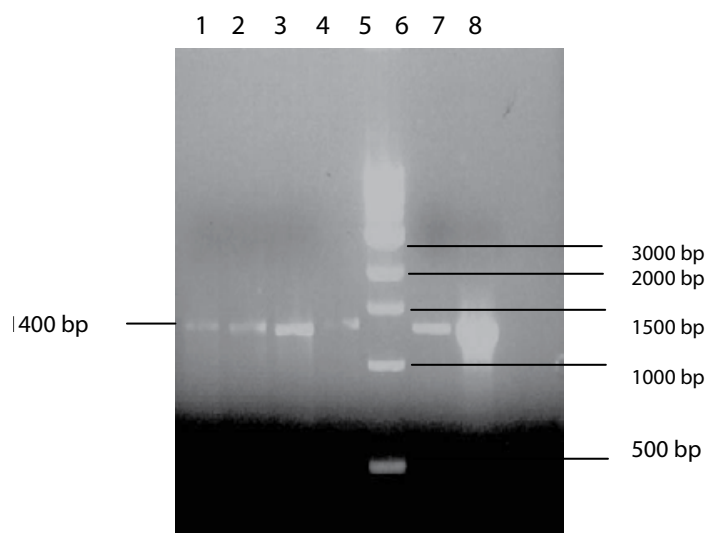

Figure 2: PCR products $(\sim 1.4 \mathrm{~kb})$ given by beta 01 and beta 02 universal primers. Lane 1- 4 : isolates $\mathrm{C} 0-1, \mathrm{C}-02, \mathrm{C} 0-3$ and $\mathrm{C} 0-4$ respectively (arrow in left), lane $5: 1 \mathrm{~kb}$ DNA, lane 6: isolate $\mathrm{C} 0-5$, lane 7: positive control, lane 8: sample from an asymptomatic plant.

extraction kit (Amersham Biosciences, UK), according to the manufacturer's protocol. The ploymerase chain reaction (PCR) was carried out using beta 01 and beta 02 universal primers ${ }^{7}$ that have been designed for highly conserved regions of all known betasatellite molecules. The set up of $25 \mu \mathrm{L}$ reaction mixture and the amplification conditions used were identical to that described in earlier studies for amplification of betasatellites. PCR amplicon of $\mathrm{C} 0-2$ isolate was recovered and cloned into pGEM TEasy Vector System (Promega, USA).

The presence of begomoviruses in the five samples was confirmed by visual clumps which resulted in chloroplast agglutination for all five isolates with leaf curl symptoms. No agglutination was observed with extracts from asymptomatic samples. The results further indicated that the monoclonal antibody SCR 60 could detect begomovirus in all five diseased plants of
C. microcarpum (Kunth) by indirect TAS ELISA tests Expected fragments of approximately $1.4 \mathrm{~kb}$ resulted in PCR with beta primers (Figure 2) indicating that a DNA betasatellite molecule is associated with the begomovirus in each plant with leaf curl symptoms. Basic local alignment search tool (BLAST) analysis of the sequence data of $1.4 \mathrm{~kb}$ product (Accession no. AM 933578) revealed that it has a maximum nucleotide sequence identity of $97 \%$ with Cotton leaf curl Multan betasatellite (CoLCMB) (Accession no. AY 795608). Based on this full-length sequence data, $\mathrm{C} 0-2$ can be considered as a strain of Cotton leaf curl Multan betasatellite according to the criterion proposed in 2008 for taxonomy of DNA betasatellites.

Although the CoLCMB was reported previously from elsewhere in the world, this is the first report of CoLCMB strain occurring in Sri Lanka. This is also the first report of a new host of CoLCMB-begomovirus complex. At present, we have no evidence for the occurrence of CoLCMB in any Sri Lankan crop plant but it is possible that $C$. microcarpum (Kunth) may serve as an alternative host of the begomovirus-CoLCMB complex.

\section{Acknowledgement}

The research support given by Dr. John Stanley of John Innes Centre, Norwich Research Park, UK in sequencing the betasatellite component and ACMV samples gifted by the Scottish Crop Research Institute, Dundee are gratefully acknowledged.

\section{References}

1. Jayaweera D.M.A. (1982). Medicinal Plants (Indigenous \& Exotics) Used in Ceylon. Part V, pp. 48-49. National Science Council (NSC) of Sri Lanka, 47/5, Maitland Place, Colombo 7. 
2. Varma A. \& Malathi V.G. (2003). Emerging geminivirus problem: a serious threat to crop production. Annals of Applied Biology 142(2): 145-164.

3. Saunders K., Salim N., Mali V.R., Malathi V.G., Briddon R., Markham P.G. \& Stanley J. (2002b). Characterization of Sri Lankan cassava mosaic virus and Indian cassava mosaic virus: evidence for acquisition of a DNA B component by a monopartite begomovirus. Virology 293(1): 63-74.

4. Zoysa I.J. (1996). Leaf curl virus of tomato in Sri Lanka. Proceedings of the Phase I Final Workshop of the South Asian Vegetable Research Network, Kathmandu, Nepal, 23-28 January, p. 265.

5. Van Slogteren D.H.M. (1955). Serological micro-reactions with plant viruses under paraffin oil. Proceeding of the Conference on
Potato Virus Disease, Lisse-Wageningen. The Netherlands, 25-29 June, 1954. pp. 51-54.

6. Muniyappa V., Swanson M.M., Duncan G.H. \& Harrison B.D. (1991). Particle purification, properties and epitope variability of Indian tomato leaf curl geminiviruses. Annals of Applied Biology 118(3): 595-604.

7. Briddon R.W., Bull S.E., Mansoor S., Amin I. \& Markham P.G. (2002). Universal primers for the PCR- mediated amplification of DNA ß. Molecular Biotechnology 20(3): 315-317.

8. Briddon R.W., Brown J.K., Moriones E., Stanley J., Zerbini M., Zhou X. \& Fauquet C.M. (2008). Recommendations for the classification and nomenclature of the DNA- satellites of begomoviruses. Archives Virology 153(4):763-781. 